\title{
Concepções e Práticas dos Visitantes do Parque do Ingá, Maringá-PR Acerca da Alimentação dos Saguis (Callithrix jacchus)
}

\section{Conceptions and Practices of Visitors from Parque do Ingá, Maringá-PR about Feeding the Marmosets (Callithrix jacchus)}

\author{
Isabella Assis Alavarse Gonzales*; Carlos Alberto de Oliveira Magalhães Júnior ${ }^{\mathrm{b}}$
}

aUNICESUMAR.

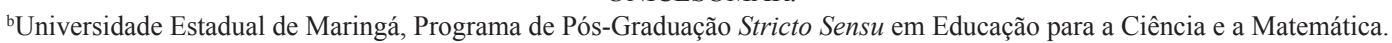

*E-mail: isabellagonzales@hotmail.com

Recebido em: 10/09/2015; Aceito em: 24/11/2015

\begin{abstract}
Resumo
A alimentação errônea dos animais nos parques urbanos tem acarretado graves problemas ao meio ambiente e também à saúde pública. Neste contexto, o presente trabalho visou investigar as concepções dos visitantes do Parque do Ingá, Maringá-PR acerca da alimentação dos saguis, bem como conscientizá-los quanto às medidas para minimizar essa problemática. Foram entrevistados 115 visitantes do Parque do Ingá e coletadas informações por meio de entrevista semiestruturada. Os dados foram analisados por meio de estatística descritiva. Os resultados revelaram que a maioria dos visitantes não costuma alimentar os animais. Percebe-se na pesquisa que a população estudada conhece a alimentação dos saguis e procura respeitá-los, não oferecendo-lhes alimentos. Acredita-se que em Maringá a população esteja informada por meio de placas de orientação existentes praticamente desde a fundação do Parque e também das diversas mídias que sempre contribuem com seus artigos informativos.
\end{abstract}

Palavras-chave: Callithrix. Educação Ambiental. Alimentação.

\begin{abstract}
The erroneous animals feeding in urban parks has caused serious problems to the environment and also to public health. In this context the present study aimed to investigate the conceptions of Parque do Ingá visitors, Maringá-PR about marmosets' feeding, as well as educate them about the measures to minimize this problem. So, 115 visitors from the Parque do Ingá were interviewed and information collected through structured interview. Data were analyzed using descriptive statistics. The results revealed that most visitors do not usually feed the animals. It is noticed in the research that the studied population knows about the marmoset's feeding and respect them not offering food. It is believed that in Maringá population is informed by signs of guidance, which exists almost since the founding of the park and also by the various media that always contribute with its informative articles.
\end{abstract}

Keywords: Callithrix. Environmental Education. Feeding.

\section{Introdução}

A alimentação errônea dos animais nos parques urbanos tem acarretado graves problemas ao meio ambiente, tendo em vista os acidentes causados aos animais silvestres quando entram em contato com a alimentação humana, as quais ocasionam patologias relacionadas aos seres humanos que antes não acometiam os animais, além de sua saída em busca de alimento podendo atacar os visitantes dos parques. Os animais que habitam os parques são silvestres, seguem o curso natural da cadeia alimentar mantendo assim o equilíbrio do ecossistema. Buscam sua alimentação na natureza e quando são alimentados com produtos inadequados, tais como doces, refrigerante, pipoca, caldo de cana, entre outros, modificam seus hábitos e colocam em risco sua sobrevivência.

Segundo Paiola et al. ${ }^{1}$, os alimentos que são deixados nas ruas ao redor das reservas, principalmente pelas pessoas da região, são fortes atrativos para os animais silvestres se arriscarem a sair de seu espaço natural e passarem a ter este hábito alimentar, já que há maior facilidade na obtenção da comida, além da presença de grãos, sementes, frutas, plantas herbáceas, entre outros deixados na pista ou próxima dela, podendo resultar no atropelamento do animal.

Segundo a mídia local, os saguis do Parque do Ingá têm saído do ambiente em que vivem à procura por alimentos. Seus alvos são visitantes e pessoas que estão caminhando no entorno do Parque com alimentos nas mãos e também as residências próximas. Ao cruzar as pistas os animais estão expostos a atropelamentos por veículos, fato que ocorre com frequência.

A questão do hábito de visitantes alimentarem os animais foi citada no Jornal de Londrina ${ }^{2}$, do município de LondrinaPR. A matéria destaca que os animais têm sido alimentados com produtos impróprios à sua dieta alimentar natural pela população da região que visita o Parque do Ingá. Na reportagem o Jornal informa, ainda, que 16 primatas, sendo 15 saguis e um macaco prego, já morreram vítimas de uma doença ainda desconhecida. Suspeitou-se na oportunidade que a origem dessa doença estivesse associada aos alimentos dos humanos, eventualmente contaminados por eles e ofertados aos animais.

A cidade de Maringá apresenta hoje três parques urbanos, 
somando 137 hectares de reserva na área urbana, contribuindo para a relação de $25,47 \mathrm{~m}^{2}$ de área verde por habitante, onde podemos encontrar espécies variadas da flora local, assim como pequenos animais silvestres. Estes bosques são ponto de encontro, local de recreação e exercícios físicos, além de referência na forma urbana, seja como ponto focal seja como limite entre os distintos bairros que os cercam ${ }^{3}$.

Criado pelo Decreto $\mathrm{n}^{\circ} 870 / 1971$, o Parque do Ingá compreende uma área de $473.300 \mathrm{~m}^{2}$, localiza-se na região central de Maringá, entre as Avenidas São Paulo e Laguna, entre as coordenadas geográficas $23^{\circ} 25^{\prime} 28^{\prime \prime}$ de latitude sul e $51^{\circ} 55^{\prime} 59^{\prime \prime}$ de longitude oeste, com altitude de 557 metros. O Parque do Ingá foi inaugurado em 10 de outubro de 1971, servindo de orgulho para a maioria dos maringaenses. É considerada uma das áreas verdes mais importantes e recreativas da região noroeste do Estado do Paraná, sendo visitado constantemente por turistas que passam por Maringá. Dentre as atividades desenvolvidas pelos frequentadores do parque, inclui ainda, passear com as crianças e a contemplação do verde, pois os caminhos para o passeio adentram a vegetação colocando o visitante em contato com a natureza, por meio de uma paisagem agradável ${ }^{4}$. Entretanto a cidade de Maringá é muito característica pelos seus diversos parques e bosques, que deram à cidade o título de Cidade Verde 5 .

O Parque está em uma área de domínio de floresta estacional semidecidual, predominando as espécies nativas, porém nas proximidades das trilhas foram introduzidas algumas espécies exóticas ${ }^{4}$.

No Paraná, as espécies de saguis Callithrix penicillata e Callithrix jacchus estão sendo introduzidas em locais onde a sua ocorrência não é natural, causando desequilíbrio e deslocamento das espécies nativas, por meio de competição, por limitação de recursos ${ }^{6}$. Segundo Passos et al. ${ }^{7}$ as duas espécies de Callithrix têm ocorrências após introduções e são confirmadas no município de Maringá. Apesar da diversidade de espécies que habitam os parques urbanos, no Parque do Ingá o animal que chama mais a atenção é o sagui de tufo branco (Callithrix jacchus), que por ser esperto e gracioso é o que mais se aproxima da população em busca de alimento.

Callithrix jacchus, também conhecido como sagui comum, é um pequeno primata neotropical, habitante das florestas do Nordeste brasileiro. Pertencente à família Callithrichidae, vive em pequenos grupos, nos quais a maioria dos membros estão relacionados. No grupo há um reprodutor feminino e muitas outras fêmeas não reprodutivas. Sua dieta geralmente é composta de frutas, néctar, flores, insetos e goma de algumas árvores da floresta. Este sagui geralmente dá à luz dois ou mais filhotes de uma só vez. Cuidado parental inclui transporte, cuidar e compartilhar comida com o recém-nascido e é realizado por todos os adultos e adolescentes do grupo ${ }^{8}$.

Membros dessa espécie têm sido, há anos, atração popular em circos e zoológicos, por sua semelhança comportamental e física com o homem; tornaram-se também populares como animais de estimação. Porém, são transmissores de diversas enfermidades e o seu convívio com o ser humano é extremamente arriscado, pois são animais susceptíveis a doenças comuns ao homem, tais como zoonoses e por meio de agressões representam risco potencial para a saúde pública. Assim, deve-se levar em consideração o equilíbrio entre os ganhos advindos dessa relação e a ocorrência de danos à saúde dos seres humanos e não humanos, pois a ocorrência do contato entre humanos e saguis é um fator de risco de grande relevância no tocante à raiva, pois os primatas não humanos são reservatórios de várias zoonoses, entre as quais a raiva, doença considerada mortal ${ }^{9}$.

Em geral, o público considerado leigo não se sente parte integrante da questão, assumindo assim uma postura alheia, por exemplo, de apenas considerar os saguis bonitinhos ou simpáticos, sem a preocupação com os possíveis desdobramentos da relação desses animais com outras espécies (em especial, a nossa) em diversos habitats brasileiros. Assim, surge a importância da participação da população para mudar essa visão parcial da relação com os saguis e a Educação Ambiental - EA pode contribuir para tal, pois melhor informadas, as pessoas terão mais instrumentos para agir consciente e ativamente, abandonando a postura contemplativa $^{10}$.

Com base no disposto, a presente pesquisa teve como objetivo analisar as concepções e práticas dos visitantes do Parque do Ingá, no município de Maringá-PR, sobre a prática de alimentar os animais, para que medidas de EA sejam formuladas aos visitantes.

\section{Material e Métodos}

A pesquisa foi parte das atividades do curso de Especialização em Ecologia e Conservação de Fauna Silvestre da Universidade Estadual de Maringá e ocorreu entre os meses de fevereiro e março de 2014, durante os fins de semana.

Esta pesquisa caracteriza-se como estudo de caso, pois é um trabalho voltado para o estudo de um caso específico em relação a práticas humanas no tocante à alimentação de um grupo de animais, que tem um valor em si. Essa abordagem procura destacar a complexidade natural das situações, demonstrando a inter-relação dos seus componentes ${ }^{11}$.

A pesquisa foi descritiva por pretender descrever as características de determinada população ou fenômeno ou o estabelecimento de relações entre variáveis, envolvendo o uso de técnicas padronizadas de coleta de dados, assumindo a forma de levantamento ${ }^{12}$.

Foram realizadas entrevistas com os visitantes do Parque do Ingá, num total de 115 indivíduos escolhidos aleatoriamente e que aceitaram participar da entrevista e assinaram o Termo de Consentimento Livre e Esclarecido - TCLE, com o propósito de investigar o conhecimento dos participantes acerca da alimentação dos saguis (Callithrix jacchus) do parque.

A coleta de informações consistiu em um questionário 
semiestruturado composto por nove perguntas, permitindo que os participantes pudessem expressar suas opiniões livremente. As perguntas relacionavam-se ao conhecimento da alimentação correta dos saguis, se costumam alimentá-los, bem como a ocorrência e a frequência em que são alimentados pela população. Os dados foram analisados por meio de estatística descritiva e representados em percentuais.

\section{Resultados e Discussão}

Compuseram a amostra 115 indivíduos, dentre estes 40,8\% (47 indivíduos) do sexo masculino e 58,3\% (67 indivíduos) do sexo feminino e um indivíduo não informou.

Outro fator levado em consideração durante a pesquisa foi a idade dos componentes da amostra, sendo descrita na Figura 1 , bem como o percentual das faixas etárias.

Figura 1: Disposição da idade entre os componentes da amostra

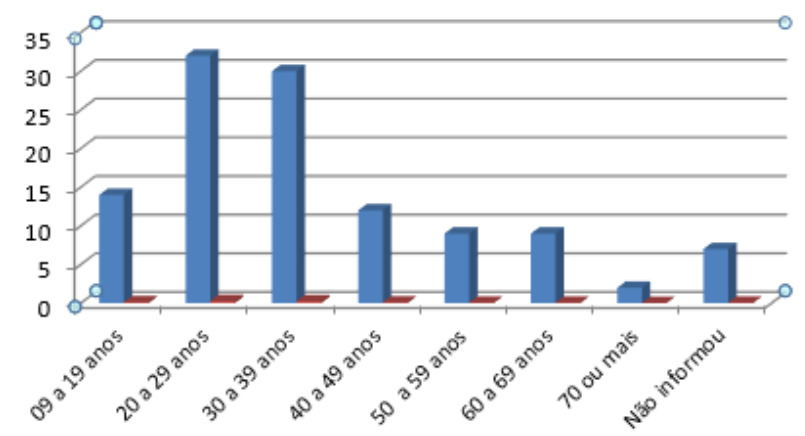

Fonte: Dados da pesquisa.

Em relação a estarem estudando no momento, 67,8\% (78 indivíduos) informaram não serem estudantes, 29,6 (34 indivíduos) informaram estarem estudando e 2,6 (3 indivíduos) não informaram.

Outro dado importante foi o grau de escolaridade dos componentes da amostra, sendo estes dispostos entre: $13,9 \%$ (16 indivíduos) com ensino fundamental, 37,4\% (43 indivíduos) com ensino médio, 21,7\% (25 indivíduos) com nível superior, 14\% (16 indivíduos) especialistas, 7\% (8 indivíduos) mestres, 3,4\% (4 indivíduos) com doutorado, $0,9 \%$ ( 1 indivíduo) com pós-doutorado e 1,7\% (2 indivíduos) não informou.

Com relação à frequência com que visitam o parque, 45,2\% (52 indivíduos) alegaram visitar regularmente, 53,9\% (62 indivíduos) alegaram não visitar regularmente o parque ou estar visitando pela primeira vez e 0,9 ( 1 indivíduo) não informou. Dentre esses visitantes frequentes 5,7\% (3 indivíduos) alegaram alimentar os saguis do parque, e os demais, 94,3\% (112 indivíduos) componentes da amostra alegaram não realizar tal prática. Esses dados podem indicar que as pessoas provavelmente estão se conscientizando dos malefícios causados aos animais quando alimentados com produtos que não pertencem a sua alimentação natural. Tendo em vista que $46,1 \%$ da amostra tem no mínimo curso superior, esta consciência da preservação do meio ambiente pode advir de conhecimentos adquiridos ao longo da trajetória universitária.

Pode-se observar que entre os indivíduos que alegaram alimentar os saguis do parque existe uma relação desta prática com a frequência de visitação, pois ao analisar as características comuns deles, constatou-se que todos são visitantes frequentes do Parque e todos referiram não conhecer as consequências de uma má alimentação para estes animais silvestres.

Segundo $\operatorname{Verdi}^{13}$, na prática, a população brasileira ainda apresenta hábitos predatórios ao meio ambiente e à sua própria qualidade de vida, mas aumenta a disposição para atitudes pró-ativas, assim como elevou-se o conhecimento sobre os problemas, sendo as ações pró-ambiente concentradas em homens e mulheres com nível mais alto de escolaridade e residentes em áreas urbanas, independentemente da renda.

Entre as justificativas dos participantes que alegaram alimentar os saguis está a de "Parecer que estão sempre com fome" e "Por prazer de meu filho ver". Em relação à pergunta sobre quais alimentos eram oferecidos, apareceram como respostas pão, bolacha e banana. Em um estudo semelhante no Parque Municipal do Cinturão Verde, no município de Cianorte-PR, com relação à frequência com que alimentam deliberadamente os animais silvestres, sete pessoas disseram fornecer frequentemente os alimentos, 16 (14\%) afirmaram alimentá-los raramente e 91 (79,8\%) informaram não realizar tal prática, mostrando que lá essa prática tem sido menos frequente ${ }^{1}$.

Quando perguntado se já viu alguém alimentar os saguis do parque 43,5\% (50 indivíduos) disseram que sim, 24,4\% (28 indivíduos) disseram que não e 32,1 (37 indivíduos) não responderam. Do total da amostra, 2,6\% (3 indivíduos) acham correto alimentar os saguis. Apesar de 43,5\% dos entrevistados afirmarem já terem visto alguém alimentar os saguis, a pesquisa mostrou que a maioria dos visitantes entrevistados não tem tal hábito. Esse dado positivo pode ter ocorrido pelo alto grau de escolaridade de uma grande parcela dos participantes ( $47 \%$ com no mínimo graduação) da pesquisa ou por estes terem se sentido inibidos em reconhecer uma prática, hoje, politicamente incorreta, tendo em vista a presença dos pesquisadores.

Para Ladeira ${ }^{14}$, a fragilidade do método de pesquisa de Observação Participante está na relação entre observador e observado, que consiste no envolvimento de ambos a fim de coletar informações corretas, porém este envolvimento pode atrapalhar a percepção, provocando interpretações errôneas.

A ministra do Meio Ambiente do Brasil, Izabella Teixeira, afirma que o brasileiro começa a tomar consciência sobre a importância de sua participação em relação a questões ambientais, sente-se parte da biodiversidade e assume, cada vez mais, suas responsabilidades ${ }^{13}$.

Quando questionados se conhecem a alimentação ideal dos saguis, 14,8\% (17 indivíduos) disseram conhecer, 72,2\% (83 indivíduos) disseram não conhecer e 13\% (15 indivíduos) não responderam. 
Sobre a alimentação correta dos saguis, $61 \% \quad(70$ indivíduos) disseram ser frutas, 2,6\% (3 indivíduos) disseram ser cereais, $1,7 \%$ ( 2 indivíduos) disse ser frutas e cereais, $3,4 \%$ (4 indivíduos) disseram outros e 31,3\% (36 indivíduos) não responderam, demonstrando que a maioria sabe que as frutas são os alimentos necessários e apropriados a esses animais.

A alimentação errônea dos animais nos parques urbanos acarreta problemas ao meio ambiente em razão de acidentes causados aos animais e aos seres humanos, conforme corroborado por Tavares ${ }^{15}$, quando afirma que uma nutrição adequada é fator determinante para um correto desenvolvimento do filhote e propicia condições para uma excelente saúde geral e desempenho futuro.

Quando questionados sobre o local no qual aprenderam sobre a alimentação correta dos saguis, 10,7\% (12 indivíduos) assinalaram mais de uma resposta, as quais foram consideradas durante as análises (Figura 2).

Figura 2: Local onde aprendeu sobre a alimentação correta dos saguis

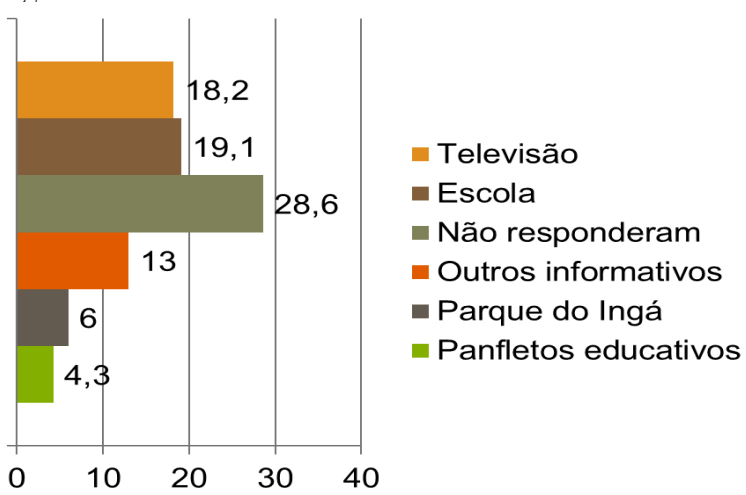

Fonte: Dados da pesquisa.

Dentre as respostas dos participantes que disseram conhecer a alimentação ideal dos saguis, 14,8\% (17 indivíduos) citaram que suas fontes de informações foram: Escola, Televisão, Parque do Ingá, Panfletos Educativos e Outros. Já em relação aos participantes que informaram não conhecer a alimentação ideal de saguis, 72,2\% (83 indivíduos) mencionaram o local pelo qual obtiveram alguma informação sobre o tema, sendo estes distribuídos entre: Televisão, Escola, Outros (Pesquisadores), Parque do Ingá e Panfletos Educativos. Alguns participantes não responderam o questionamento sobre o conhecimento da alimentação ideal dos saguis, 13\% (15 indivíduos) porém, manifestaram algum conhecimento com base nas seguintes fontes: Televisão, Outros, Escola, Panfletos Educativos e Parque do Ingá.

Sobre o conhecimento acerca da alimentação inadequada dos saguis, 60,9\% (70 indivíduos) responderam não conhecer suas consequências, $37,4 \%$ (43 indivíduos) responderam conhecer os efeitos causados a esses animais quando expostos a uma má alimentação e 1,7\% (2 indivíduos) não respondeu. Quando perguntados sobre o conhecimento das consequências de uma alimentação inadequada, $72 \%$ (31 indivíduos) citaram algum efeito causado ao animal na natureza, entre eles: problemas intestinais, problemas dentários, agressão dos bichos à procura de comida, intoxicação alimentar, morte, problemas de saúde, passar mal, doenças, obesidade, perda de peso, reprodução descontrolada, domesticação, mudanças comportamentais, transmissão de doenças e disfunção metabólica. Foram citados corretamente pelos entrevistados os efeitos negativos na saúde desses animais, pois conforme afirma Tavares ${ }^{15}$, uma nutrição inadequada, excesso ou deficiência de nutrientes pode resultar em alterações fisiológicas, predispondo o organismo animal a sérios problemas, como incorreto desenvolvimento corporal e constituição óssea, obesidade, além de alterações metabólicas e reprodutivas.

De acordo com Nakamura ${ }^{10}$, quando os saguis obtêm a comida oferecida artificialmente seu comportamento reprodutivo pode ser alterado, a energia extra adquirida com essa alimentação pode influenciar na ovulação das fêmeas, podendo resultar em mais filhotes por gestação. Como os animais apresentam a necessidade biológica de procurar a comida, Sgai ${ }^{16}$ demonstra a predileção de muitas espécies em trabalhar para comer, sugerindo que a disponibilidade de alimentos pode gerar uma frustração e ser estressante.

Referente a placas de orientação no parque, 42,7\% (49 indivíduos) afirmaram não ter visto nenhuma placa, 52,1\% (60 indivíduos) afirmaram ter visto alguma placa de orientação e $5,2 \%$ (6 indivíduos) não responderam.

Apesar de a maioria referir que visualizou as placas de orientação, um grande número de visitantes informou que não conseguiram visualizá-las. O Parque do Ingá, segundo informação de sua direção, contém três placas de orientação solicitando aos visitantes que não alimentem os animais, estando elas assim distribuídas: uma no Parque do Japão, uma na cantina e outra na trilha, como constatamos nesta unidade de conservação. As placas de orientações têm como objetivo informar e orientar o comportamento dos visitantes, assim, devem estar instaladas em local que facilite a visualização por parte deles.

À medida que as pessoas foram sendo entrevistadas, elas questionavam qual era a alimentação ideal dos animais, assim, aproveitávamos a oportunidade para orientar os visitantes sobre os hábitos alimentares e comportamentais dos animais e como respeitar seu habitat natural. Tal interesse demonstra que hoje significativa parte da população tem grande preocupação com a temática do meio ambiente.

Diante dos resultados apresentados, a Educação Ambiental é vista como uma ação relevante para o desenvolvimento de um novo perfil de cidadão, que se preocupe com suas ações, impactos e crises ambientais e que saiba conduzir suas atuações para uma vida mais sustentável.

De acordo com Marcatto ${ }^{17}$, a sociedade tem reconhecido os impactos diretos na qualidade de vida e na própria sobrevivência da espécie. Assim, são relevantes trabalhos de 
sensibilização relacionados aos problemas ambientais, como os gerados pela má alimentação dos saguis. Essa unidade de conservação é um ambiente potencial para vinculação de informações e de construção do conhecimento que promova a EA.

\section{Conclusão}

Para que a população possa conviver com os animais silvestres, assim como preservar a fauna e a flora, é necessária a sensibilização e o conhecimento dos hábitos e alimentação dos animais para manter o equilíbrio do ecossistema.

Verifica-se, por meio de relatos de alguns entrevistados, que existe a prática da alimentação dos visitantes aos animais do parque, tendo em vista que 43,5 afirmaram ter presenciado tal prática. Porém, percebe-se na pesquisa que a população estudada conhece a alimentação dos saguis e procura respeitálos não oferecendo-lhes alimentos.

Acredita-se que em Maringá a população esteja informada por meio de placas de orientação, existentes praticamente desde a fundação do Parque e também das diversas mídias que sempre contribuem com seus artigos informativos. Apesar das placas de orientação dentro e ao redor do parque para não alimentarem os animais, alguns visitantes alegaram não as terem visto, por isso faz-se necessário ampliar a quantidade dessas placas e colocá-las em locais estratégicos para sua melhor visualização.

Ações educativas direcionadas a informar melhor os visitantes sobre a biologia dos saguis, o tipo de sua alimentação e suas relações ecológicas poderão ser atividades que proporcionem mudanças no comportamento daquelas pessoas que ainda permanecem alimentando de forma equivocada esses animais.

Mesmo a pesquisa tendo um resultado positivo em relação à conservação e respeito aos saguis, políticas públicas devem ser implementadas para manter esses parques em funcionamento, assim como orientação constante aos visitantes, mas antes de tudo educação ambiental nas escolas, e até mesmo nas unidades de conservação, para que crianças e adultos incorporem essas práticas em seu cotidiano, objetivando que a população humana e os animais silvestres possam conviver melhor, sem tantos danos para estes últimos, e assim preservar o ambiente.

\section{Referências}

1. Paiola GC, Domeneguetti L, Merlin J, Barros JJC, Ortêncio Filho H, Magalhães Júnior CAO. Percepção de moradores de Cianorte sobre a prática de alimentar animais silvestres. UNOPAR Cient Ciênc Human Educ 2012;13(2):81-6.

2. Maria MP. Macacos encontrados mortos no Parque do Ingá tinham herpes. J Londrina 2009. [acesso em 20 jul 2015]. Disponível em http://www.jornaldelondrina.com. br/online/conteudo.phtml?tl=1\&id=887021\&tit=Macacosencontrados-mortos-no-Parque-do-Inga-tinham-herpes.

3. Rego RL. Maringá: o espaço e a forma urbana. In: Seminário de História da Cidade e do Urbanismo 2002;7(2). [acesso em
26 jun 2015]. Disponível em http://unuhospedagem.com.br/ revista/rbeur/index.php/shcu/article/view/908/883.

4. Bovo MC, Amorim MCCT. Análise e diagnóstico dos parques urbanos em Maringá (PR) Brasil. Geo UERJ 2011;2(22):32349.

5. Camolezi BA, Martin MEE. Observação de fauna silvestre em ambientes urbanos na cidade de Maringá - PR em 2008. In: Anais do $6^{\circ}$. Encontro Internacional de Produção Científica Cesumar; 2009 out 27-30; Maringá, Brasil. Anais... Maringá: Cesumar; 2009.

6. Traad RM, Leite JCM, Weckerlin P, Trindade S. Introdução das espécies exóticas callithrix penicillata (geoffroy, 1812) e callithrix jacchus (linnaeus, 1758) em ambientes urbanos (primates: callithrichidae). Rev Meio Amb Sustentabilidade 2012;2(1).

7. Passos FC, Miranda JMD, Aguiar LM, Ludwig G, Bernardi IP, Moro-Rios RF. Distribuição e ocorrência de primatas no estado do Paraná, Brasil. In: Bicca-Marques JC. A primatologia no Brasil: volume 10. Porto Alegre: EDIPUCRS; 2006.

8. Oliveira, AL, Malagueno E, Telles MAS, Madruga MH, Santana, JV. Experimental schistosomiasis in the Common Marmoset Callithrix jacchus. Rev Soc Bras Med Trop 2004;37(3):222-8.

9. Aguiar TDAF, Costa EC, Rolim BN, Romijn PC, Morais NB, Teixeira MFS. Risco de transmissão do vírus da raiva oriundo de sagui (Callithrixjacchus), domiciliado e semidomiciliado, para o homem na região metropolitana de Fortaleza, Estado do Ceará. Rev Soc Bras Med Trop 2011;44(3):356-63.

10. Nakamura EM. Convívio entre saguis e pessoas: experiências no Parque Ecológico do Córrego Grande e entorno, Florianópolis - SC. Monografia [Graduação em Ciências Biológicas]. Universidade Federal de Santa Catarina; 2009.

11. Ludke M, André M. Pesquisa em educação: abordagens qualitativas. São Paulo: EPU, 1986.

12. Gil AC. Metodologia do ensino superior. São Paulo: Atlas; 2005.

13. Verdi L. Meio ambiente: o brasileiro está mais consciente. 2012. [acesso em 20 jun 2014]. Disponível em http://www. mma.gov.br/informma/item/8386-o-que-o-brasileiro-pensado-meio-ambiente-e-do-consumo-sustent $\% \mathrm{C} 3 \% \mathrm{~A} 1$ vel.

14. Ladeira WT. Teoria e métodos de pesquisa qualitativa em sociolinguística interacional. Rev Ciênc Hum 2007;7(1):4356.

15. Tavares HL. Alimentação e nutrição de animais silvestres. In: Anais do $24^{\circ}$ Congresso Brasileiro de Zootecnia; 2004 maio 12-14; Vitória, Brasil. Anais... Vitória: Universidade Federal do Espírito Santo; 2014.

16. Sgai MGFG. Avaliação da influência das técnicas de enriquecimento ambiental nos parâmetros endócrinos e comportamentais de Callithrix penicillata (sagui-de-tufospretos) mantidos em estabilidade social e isolados. Dissertação [Mestrado em Reprodução Animal] - Universidade de São Paulo; 2007.

17. Marcatto C. Educação ambiental: conceitos e princípios. Belo Horizonte: FEAM; 2002. 